\title{
DRIVER PRETESTING SYSTEM IN ZIMBABWE: AN ANALYSIS OF IMPACTS AND PERCEPTIONS
}

\author{
TATENDA MBARA \\ tmbara@uj.ac.za \\ Department of Transport and Supply Chain Management \\ University of Johannesburg
}

\begin{abstract}
In pursuance of the need to curb corruption in the learner driver testing process as well as enhancing road safety by improving driving skills, the Minister of Transport and Communications in Zimbabwe announced, on 7 July 2007, a new and unique drivertesting procedure which was implemented with effect from 1 September 2007. The new system involved the introduction of a pretesting agent acting between driving schools and the driver competence-testing department. A wholly Government-owned company was given the responsibility to pretest all learner drivers before they proceeded to the final competence test. The objective of this paper is to assess the impacts of driver pretesting on pass rates as well as ascertaining stakeholder and public views and perceptions on corruption, the necessity for driver pretesting and the lessons learnt.
\end{abstract}

\section{INTRODUCTION}

Until 31 August 2007, learner driver testing in Zimbabwe was carried out directly by the Vehicle Inspection Department (VID), a Government department responsible for the technical inspection of vehicles for roadworthiness as well as testing learner drivers for driving competence. While the majority of learner drivers were going through driver training schools, the system could not preclude self-trained individuals from booking with the VID for a driving competence test. This system provided a direct interface between driving school instructors and the VID. On 7 July 2007, the Minister of Transport and Communications announced and directed a new driver licensing procedure which was implemented on 1 September 2007. The new system involved the introduction of a pretesting agent to act between driving schools and the VID. A wholly Government-owned company which supplies vehicles and related equipment to Government and the private sector, CMED Private Limited (hereinafter referred to as CMED), was given the responsibility to pretest all learner drivers before proceeding to the VID. According to the Minister, the major reasons for bringing in an intermediate assessor were primarily to: 
- curb corruption at the VID, which was alleged to license incompetent drivers who are a menace on the roads

- improve driving skills of drivers in order to reduce carnage on the roads, following a spate of road accidents and loss of lives. It was the Minister's view that these accidents could have been avoided if the drivers had been properly trained.

\section{PURPOSE OF THE STUDY}

The Minister of Transport and Communications intended to address a safety problem which is of great concern not only in Zimbabwe, but worldwide. It is however, instructive to note that the pretesting measure that was introduced by the Minister was a directive and a unilateral decision that was made solely by the Minister. The "policy" measure was not defined in terms of exactly what the pretesting agent, CMED, was required to do, was not debated in Parliament or at Cabinet level, nor was it made available for public scrutiny before its introduction. Apart from pronouncing the policy measure, there were no arrangements put in place to monitor and evaluate the success or otherwise of the newly introduced driver pretesting system. It was in respect of the Minister's faith in the sole policy measure which was introduced with no arrangements to monitor the outcome that prompted the author to undertake the study. This paper therefore, seeks to assess the short-term impacts of the driver pretesting measure on pass rates, corruption and to a lesser extent improvement in driving skills. It also attempts to draw on the lessons learnt by critically examining the outcomes and the procedure taken to introduce the driver pretesting policy measure.

\section{LITERATURE REVIEW}

Worldwide, road accidents are a major cause for much concern. According to the World Report on Road Traffic Injuries and Prevention (2004), approximately 1.2 million people are killed in road accidents annually. Projections indicate an increase of about 65\% in road traffic deaths by 2020. It is also estimated that road traffic accidents are likely to be the third leading cause of premature death worldwide by 2020 if there are no measures put in place to reverse the trend (ibid.). Currently road accidents are ranked ninth. Clearly, road traffic accidents are a major global challenge requiring concerted efforts for effective and sustainable prevention. As most road accidents are primarily a consequence of errors resulting from driver behaviour, proper driver training is therefore essential to improve driver competency and in turn enhance safety. A study by Baker (2004) concluded that professionally trained drivers were more careful in their driving habits in comparison to their non-professionally trained counterparts. Another study by Mayhew and Simpson (2002) also alluded to the fact that educational/training programmes are likely to be effective in reducing collisions. 
Although each country may have its own unique driver testing system, in common practice it consists of a theory and a practical test. The theory test usually leads to a driver's learner or provisional permit/licence. Some countries have made visual acuity tests compulsory and any potential driver failing the test is not allowed to be a learner driver. Another test which increasingly is being adopted worldwide is the hazard perception test in which a learner driver is tested on the ability to anticipate and respond to hazards. Fisher, Pollatsek and Pradhan (2006) found substantial improvements in "recognizing potential risks" by young drivers after they had attended and participated in a hazard test computer programme.

Some countries (e.g. Ireland, Canada, Australia, USA) view learner driving as a process in which the licence has to be acquired in stages over a fairly long period. The process is known as the Graduated Driver Licensing (GDL) system and in some countries mainly targets young and inexperienced learner drivers who have a greater risk of causing accidents. In the state of New South Wales in Australia, there are four stages a learner driver has to go through in order to obtain a licence, namely: the driver knowledge test, the driving test to gain a P1 licence, the hazard perception test to gain the P2 licence and the driver qualification test to gain the full licence (New South Wales Government, 2007). According to Foss (2007), the GDL "transforms non-drivers into reasonably safe drivers while minimising the risks as they learn". In other words, the acquisition of driving experience is a process and driving privileges are earned over time as skills are gained. Countries that have implemented the GDL system have recorded a reduction in crash rates.

Corruption plays a significant role in traffic fatalities in the developing world according to Anbard, Escaleras and Register (2006). Corruption, in the form of bribes, kickbacks and extortion, is common in the transport industry as a whole. Its prevalence is not difficult to comprehend. Paterson and Chauduri (2007) attributed such high levels of corruption to the nature of the industry where "the large number of tangible goods and services such as permits, licences, contracts with multiple points at central and local levels lend themselves to corruption". The level of its prevalence can be facilitated by weak institutional structures and networks of co-operating agents (Chauduri, 2007; Djankov, Mullainathan \& Sequeira, 2008). Specific areas in relation to the transport service sector which are prone to corruption include, inter alia: bribes paid to public service officials for the issuance of driver and vehicle licences; public service permits; and bribes paid to law enforcement agents to avoid higher charges or prosecution for non-roadworthy vehicles and traffic infringements. Bertrand, Djankov and Mullainathan (2006) provide disturbing evidence of corruption in learner driver competency tests where competent drivers are failed while incompetent ones are passed. In their study, Bertrand et al. (2006) observed the deliberate creation of red tape which resulted in "arbitrarily failing drivers independent of their actual driving skills". There are high social costs associated with such practices, as incompetent drivers endanger safety and the competent ones become frustrated and demoralised. 


\section{OVERVIEW OF ROAD ACCIDENTS IN ZIMBABWE}

In 2002 (latest official census figures), the number of injury accidents per 100000 people and persons killed per 100000 people were 121.5 and 18.1 respectively and these rates have been increasing on an annual basis. According to the Zimbabwe Republic Police (the Herald, 20 July 2009), road accidents are responsible for 350 fatalities per year. Using the current estimated population of 14 million, the rate of accidents equates to approximately 35 fatalities per 100000 people. This is an extremely high rate, considering that the 10 most highly motorised countries (HMCs) have an average fatality rate of about 12 per 100000 people. In addition, such high accident rates are occurring notwithstanding a significant reduction in the number of vehicles moving on the roads due to an unprecedented economic downturn that has characterised the Zimbabwean economy since 2000. The economic downturn resulted in shortages of fuel and consequently a significant proportion of vehicles were grounded.

Major road accident disasters are of concern to both Government and the public. As illustrated in Table I these involve public transport vehicles, particularly the small kombis (locally known as commuter omnibuses), and clearly affect the vulnerable groups such as the poor who cannot afford private means of transport.

Table I: Notable road accident disasters (2003-7)

\begin{tabular}{|c|l|c|}
\hline Year & Disaster & Deaths \\
\hline 2003 & Tombs Motorways (Selous) & 21 \\
\hline 2003 & Shurugwi bus accident & 12 \\
\hline 2003 & Plumtree bus accident & 17 \\
\hline 2004 & Commuter omnibus accident (going to South Africa) & 14 \\
\hline 2004 & Shamva (Palmgrove lorry) & 22 \\
\hline 2004 & Commuter omnibus (Midlands) & 10 \\
\hline 2006 & Commuter omnibus (Mberengwa) & 10 \\
\hline 2006 & Commuter omnibus (Harare) & 11 \\
\hline 2006 & Nyamweda bus accident (Midlands) & 10 \\
\hline 2006 & Musengi/twin cab accident & 14 \\
\hline 2006 & Lorry (Harare - Chirundu accident) & 20 \\
\hline 2007 & Tynwald (commuter omnibus/train accident) & 37 \\
\hline 2009 & Munyati river bus accident & 30 \\
\hline 2009 & Beatrice - lorry/bus accident & 41 \\
\hline
\end{tabular}

Source: Compiled from information provided by the Department of Civil Protection and Zimpapers Library searches

The statistics in Table I show that the number of fatalities in major accident disasters has increased in the latter years. According to the Zimbabwe Traffic Safety Council (ZTSC), the 
main cause of accidents is human error which accounts for nearly $90 \%$ of all road accidents. However, human error goes beyond the inability of a driver to properly control and manoeuvre the vehicle to prevent an accident. The attitude of the driver and the inappropriate decisions taken while driving also constitute human error. Speeding, overtaking on the wrong side, going through red traffic signals, driving on shoulder lanes and crossing flooded rivers are examples of common driving practices that cause accidents in urban areas and the main trunk roads in Zimbabwe. Thus, road accidents are a consequence of not only a driver's inability to physically manoeuvre the vehicle but also the driver's attitude in respect of decisions she or he takes while on the road.

The Tynwald commuter omnibus/train accident cited in Table I that shocked the country when 37 people died as a result, prompted the Minister of Transport and Communications to announce a new driver licensing procedure on 7 July 2007. It is therefore pertinent to examine the accident in detail, and this is provided in Box 1 below.

Box 1: The Tynwald commuter bus/train disaster

The Tynwald commuter omnibus/train accident occurred at 0530 hours on 6 March 2007, when a commuter omnibus failed to give way to an oncoming train at a grade level crossing. The majority of passengers in the midi-bus were informal traders, who were travelling to the market to buy market gardening products for resale.

Zimbabwean officials attributed the accident to three (3) factors. Firstly, the driver was blamed for failing to stop before entering the level crossing (human error) as required by the road traffic regulations. Secondly, the rail signals were not working and there were no booms to prevent the driver from entering the level intersection. Thirdly, visibility was poor due to tall grass in the vicinity of the intersection.

The driver was over the speed limit and was playing music on the radio at high volume; he even failed to heed to the warning from passengers of the impending danger. The commuter omnibus which was licensed to carry 32 passengers was carrying 49 passengers at the time the accident occurred. Thirty seven (37) passengers including the driver died in the accident.

Police records established that the vehicle in question had previously undergone 2 road fitness tests at the VID and failed. The vehicle, which was old, was being operated without a certificate of fitness and thus it was not roadworthy. The driver was also found to be below the stipulated 25 years required to drive a public passenger service vehicle in Zimbabwe.

For the purposes of mustering resources to assist the victims, the accident was declared a national disaster in terms of the relevant Act. 
It is against the above backdrop of a high rate of accidents and in particular the Tynwald commuter omnibus/train disaster that the Minister was prompted to introduce new driver testing measures. The new procedure involves the introduction of a pretesting authority acting between the driving school and the VID driving examiners. As stated in the introductory section, the major reasons for bringing in this pretesting authority were primarily to improve driving skills as well as to address the corruption that was allegedly taking place at the VID.

\section{STUDY METHODOLOGY}

The study relied on both primary and secondary data, and information that was collected from the main stakeholders comprising CMED and the VID personnel responsible for driver pretesting (management and assessors), driving schools (both owners and instructors), ZTSC and the Ministry of Transport and Communications. Data on learner drivers registering for competency tests and pass rates was obtained from the VID and CMED for 12 months before and 12 months after the introduction of learner driver pretesting. Information on major stakeholder perceptions on the necessity of pretesting, corruption and contribution of pretesting to safety enhancement were collected using unstructured questionnaires.

A sample of 60 learner drivers were interviewed (face to face) using a structured questionnaire at both CMED and the VID irrespective of whether they had passed or failed. The face-toface interview was ideal and allowed probing on issues that needed clarification. It proved very difficult to balance the number of those who had passed with those who failed as most learner drivers in the latter group turned down the invitation for an interview due to frustration. Information collected was on costs incurred by learner drivers, views on the necessity for pretesting, existence of corruption and contribution to learner driver pretesting to safety enhancement.

A focus group discussion (FGD) was conducted with members of the public to ascertain their views on driver pretesting. This comprised about 30 people who happened to be within the vicinity of the CMED offices but with no business at CMED. Information collected revolved around the necessity of pretesting and its contribution to safety enhancement and corruption mitigation.

Valuable information was obtained from merely observing people's behaviour and activities during the course of their work. These observations were made at the CMED testing premises. 


\section{STUDY FINDINGS}

\section{Learner driver competence testing process prior to pretesting}

The learner driver testing procedure prior to the introduction of pretesting is depicted in Figure 1.

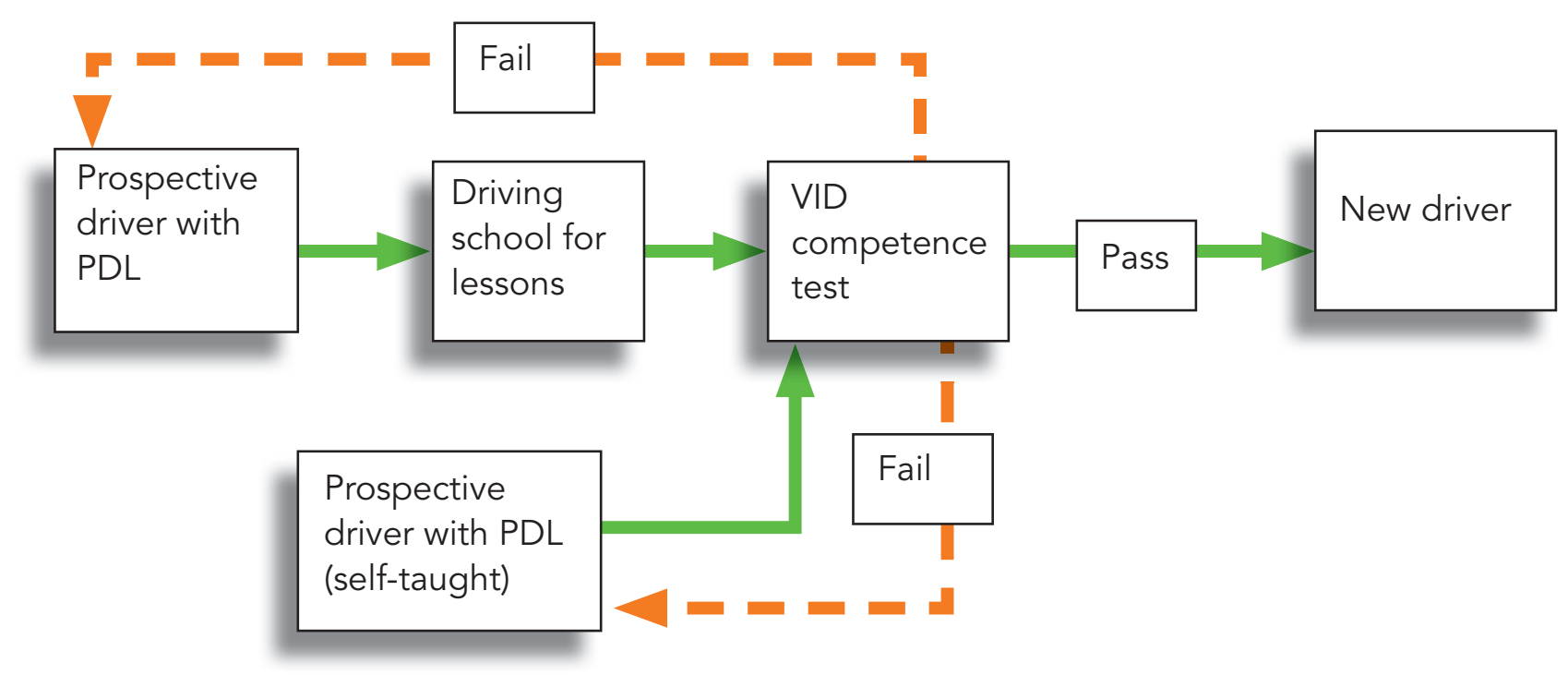

Figure 1: Learner driver testing system prior to pretesting

Source: Developed by author from procedure information provided by the VID

The testing process started with the prospective driver acquiring and mastering the Highway Code and sitting for a written test at the VID. The learner driver passing the test was given a Provisional Driver's Licence (PDL), which is valid for 12 months. The PDL enabled the learner driver to undertake lessons either with a driving school or privately (being taught by a family member). The learners (from driving schools or those who were self-taught) made a booking with the VID for a competency test whenever they felt ready for the test. It is the direct interface between the driving schools and the VID which was alleged to create an environment conducive to corruption. This was compounded by the long lead time stretching to several weeks for a learner driver to secure a slot to undertake the actual competency test. The barrier created by the non-availability of immediate testing slots encouraged unscrupulous learner drivers to pay a bribe (unauthorised fee) in order to jump the queue. Secondly, this long period between the booking and appointment dates enabled driving school instructors to connive with assessors.

\section{Learner driver competence testing process after pretesting}

The steps for learner driver testing described above up to the point that a learner driver acquires a PDL are similar in the new driver testing procedure. Figure 2 illustrates the new learner driver testing procedure that was introduced with effect from 1 September 2007. 


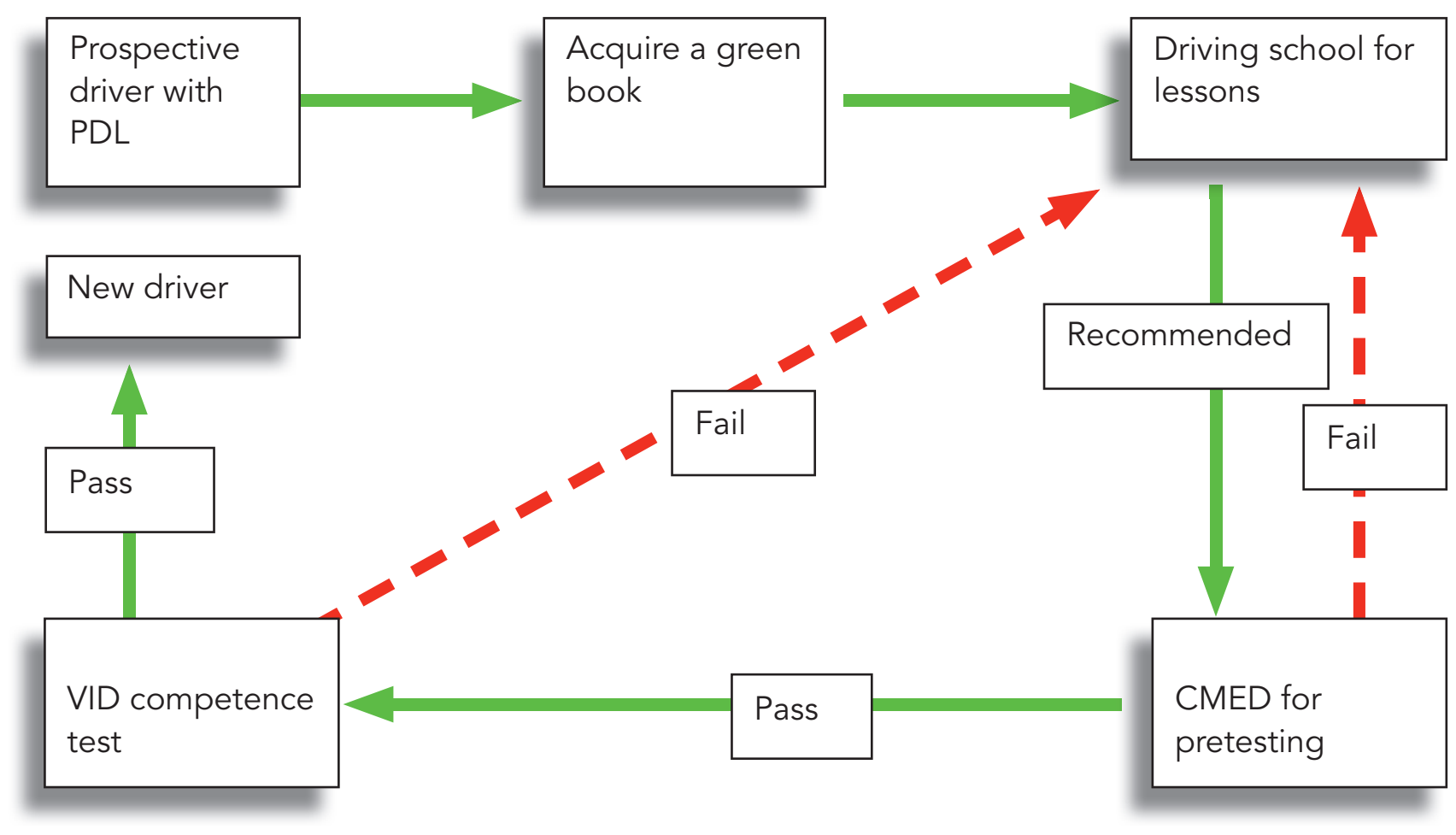

Figure 2: New learner driver testing system

Source: Developed by author from procedure information provided by the VID

After obtaining a PDL, it is now mandatory for every learner driver to register with a recognised driving school as well as buying a green book containing the curriculum that guides both the instructor and learner in assessing the latter's progress. The learner driver has to undertake the recommended 25 lessons. Once the instructor is satisfied that the learner driver is ready for a competency test, a booking for pretesting is made at CMED by the driving school. The CMED test is an exact duplication of the VID test. Learner drivers who pass the CMED test proceed to the VID on the same day, unlike in the past where one had to wait for weeks to be tested. Learner drivers who fail the CMED pretest are referred back to the driving schools. Upon passing the VID competence test, a licence is then issued. Learner drivers who fail a competence test (CMED or VID) are allowed to rebook only after seven days. This period enables the prospective driver to undertake further driving lessons with the driving school especially in those areas deemed unsatisfactory.

\section{Demand for competence tests and learner driver performance}

In this section a comparison is made between the number of learner drivers booking with the VID for the competence tests and success rates in the before and after pretesting period. The study compares the situation 12 months prior to pretesting with that of 12 months after the introduction of pretesting.

There has been a considerable decrease in the total number of learner drivers tested in 2007-8 in comparison to 2006-7. Nationally, the number of people tested at the VID in 
2006-7 were 131731 compared to 55124 who were tested at CMED in 2007-8, a 58\% decrease. At the Eastlea depot (the largest testing centre in the country), the percentage decrease equated to 64\%, as 21174 were tested in 2007-8 compared to 59068 in 2006-7. Table II shows the monthly and total learner drivers tested nationally and at Eastlea depot before and after the introduction of driver pretesting.

Table II: Learner drivers tested before and after the introduction of pretesting

\begin{tabular}{|c|c|c|c|c|}
\hline Month & \multicolumn{2}{|c|}{ National } & \multicolumn{2}{c|}{ Eastlea Depot } \\
\hline & Before pre-testing & After pre-testing* & Before pre-testing & After pre-testing \\
\hline September & 9248 & 1802 & 4631 & 2644 \\
\hline October & 8959 & 3846 & 4493 & 1820 \\
\hline November & 10806 & 4849 & 4992 & 1321 \\
\hline December & 10404 & 4190 & 4914 & 1165 \\
\hline January & 10175 & 5496 & 5241 & 1742 \\
\hline February & 10110 & 4992 & 4659 & 2052 \\
\hline March & 12200 & 5190 & 5284 & 1998 \\
\hline April & 8833 & 5513 & 4310 & 2246 \\
\hline May & 11076 & 5573 & 4581 & 1635 \\
\hline June & 11918 & 4958 & 4779 & 1688 \\
\hline July & 12328 & 4348 & 6046 & 1550 \\
\hline August & 15674 & 4367 & 5138 & 1313 \\
\hline Total & $\mathbf{1 3 1 7 3 1}$ & $\mathbf{5 5 1 2 4}$ & $\mathbf{5 9 0 6 8}$ & $\mathbf{2 1 1 7 4}$ \\
\hline
\end{tabular}

* Learner drivers reporting at the pretesting agent

Source: VID and CMED

While the number of learner drivers tested by the VID decreased considerably, the pass rate increased as evidenced by Figures 3 and 4. The average pass rate (nationally) was only 25\% in 2006-7 compared to $40 \%$ in 2007-8. At the Eastlea depot the pass rates for $2006-7$ and $2007-8$ were $25 \%$ and $44 \%$ respectively. 


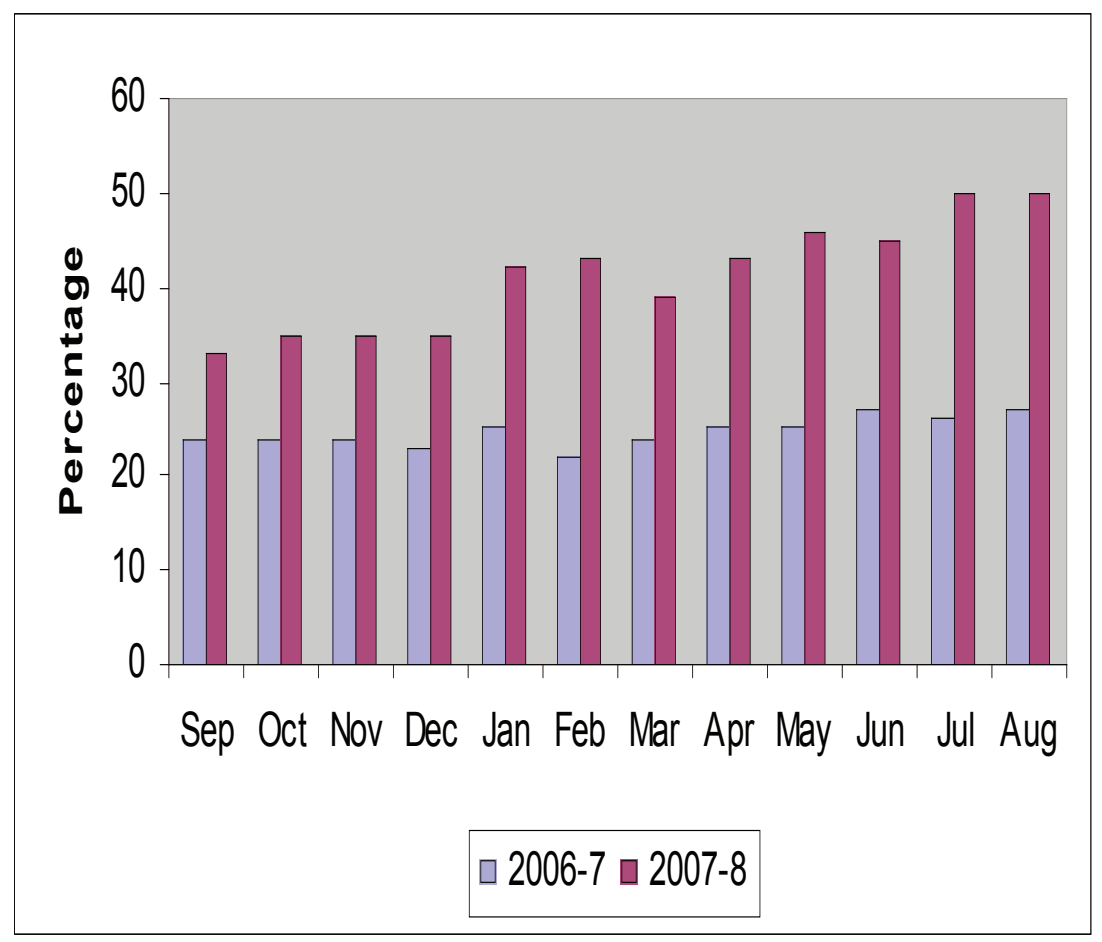

Figure 3: Comparison of 2006-7 \& 2007-8 pass rates (National)

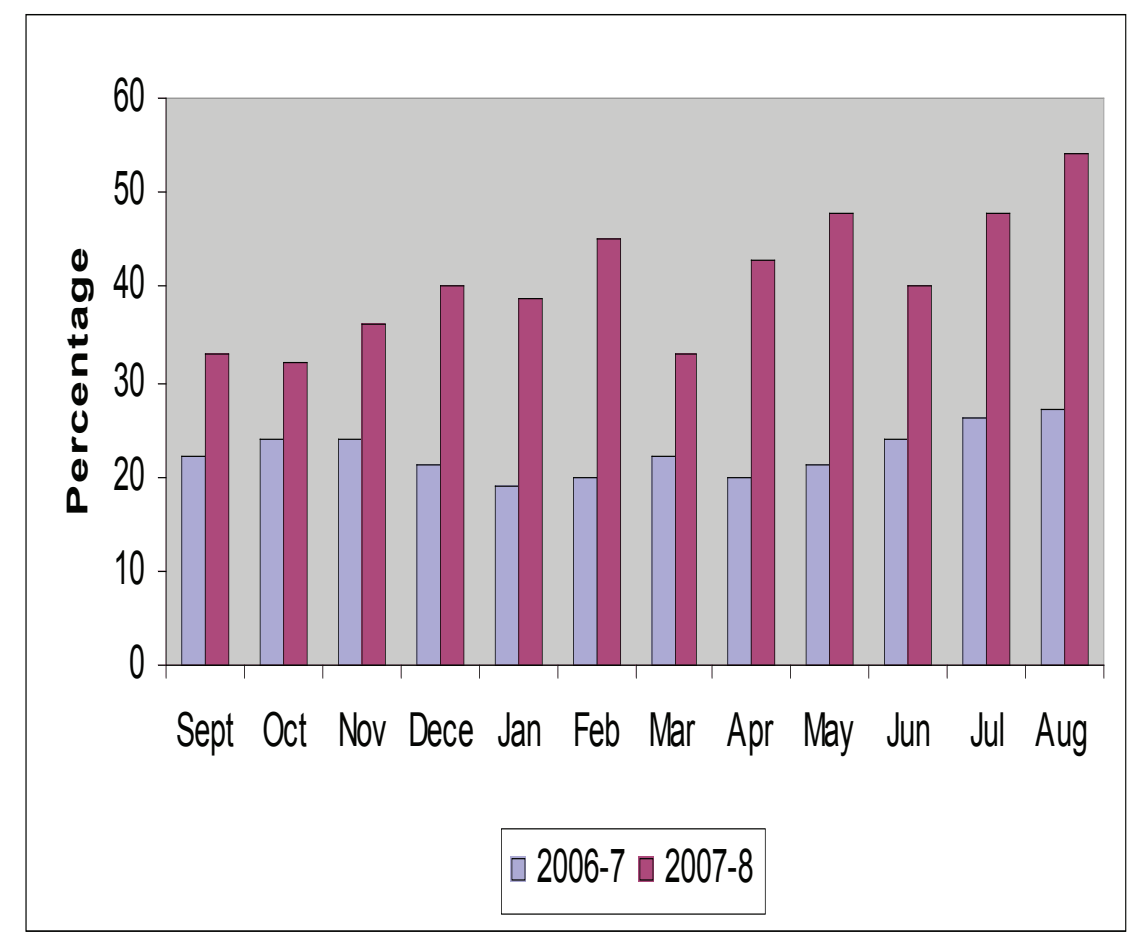

Figure 4: Comparison of 2006-7 \& 2007-8 pass rates (Eastlea depot)

The unprecedented decline in the number of learner drivers tested and increase in pass rates can be attributed to a number of factors. Firstly, training of learner drivers has become more rigorous in comparison with the period prior to September 2007 when prospective drivers would book for a VID test without undertaking proper training. Even self-taught 
learner drivers would also try their luck and book for a competence test. The new driver training system requires a learner driver to undertake a recommended 25 lessons with a registered driving school before proceeding to CMED for a pretest. Thus, the decline in the number of people being tested and increase in pass rates may be indicative of the fact that the new system has reduced the number of incompetent learner drivers being tested at the VID. Secondly, the cost of obtaining a driver's licence continues to increase in pace with inflation, dissuading some prospective drivers from taking competence tests. In addition to high charges due to inflation, the long testing chain has also increased the number of points where payments are required. The cost issue is elaborated on in a subsequent section.

Changes in the number of people tested and pass rates can only become meaningful when subjected to statistical tests. Therefore, statistical tests were computed to ascertain whether the changes are significant. The changes in both cases (that is, changes in number of learner drivers being tested and pass rates) are significant. There has been a real decline in the number of learner drivers tested at the VID $t(22)=-15.88, p<0.000)$ and a real increase in pass rates $t(22)=-9.44, p<0.000)$.

\section{Perceptions on the necessity of driver pretesting}

Stakeholders interviewed to ascertain their perceptions on driver pretesting expressed mixed feelings on its necessity. From a survey of 60 learner drivers (45\% female and 55\% male) at both CMED and the VID, 32 (54\%) expressed the view that pretesting was necessary while $28(46 \%)$ thought that it was unnecessary. The sample of 60 learner drivers (comprising 40 who had passed and 20 who had failed) was clearly biased towards those who had passed. It was not possible to get a balance as most learner drivers who had failed were too frustrated to be interviewed.

A close analysis of the data indicated that those who had passed tended to express a positive view while those who failed had a negative perception. The common view from the learner drivers who held a positive view of pretesting was that it is necessary in preparation for the VID competence test. As two interviewees put it:

Pretesting is necessary because learner drivers are given something like a mock test before proceeding to VID. [Female learner driver]

Pretesting is good as it provides adequate training to an individual and it is dangerous for one to get onto the road without having been fully prepared. A genuine driver will tell you that this is something which is necessary. [Male learner driver]

The group that was not in favour of pretesting argued that the exercise was costly and a repetition of what the VID and driving schools were doing. Two learner drivers had this to say: 
Pretesting is not supposed to be there at all. It's an extra cost to us. I do not know why I should be tested twice. This is what is fuelling corruption. It's to do with the long chain. [Male learner driver]

Those who make bookings on behalf of learner drivers charge exorbitant fees and allege that part of the money is a service charge. One also has to pay twice when booking the driving school vehicle, for CMED pretesting and VID test. [Female learner driver]

There were no noticeable differences between male and female respondents on their views of pretesting.

Proprietors of driving schools and their instructors are vehemently opposed to driver pretesting and were unanimous in their view that pretesting should not be there. Apart from the issue of costs, they also pointed out that there was no value addition as CMED and the VID were doing exactly the same thing. However, the main reason for their opposition to pretesting (although they were reticent about it) is to do with the reduced frequency they take clients to the VID which has reduced their income.

CMED, ZTSC, the VID and other Government public service departments are by and large supportive of driver pretesting. There was consensus that the previous driver training system produced drivers who were not properly trained. Therefore, in principle the driver pretesting system is perceived to be good but would require improvement particularly in resourcing CMED with appropriate vehicles and personnel.

From the FGD conducted, the public expressed serious reservations on learner driver pretesting. The public raised concerns that CMED and the VID were doing the same thing and argued that a proper study akin a cost-benefit analysis should have been conducted prior to the introduction of learner driver pretesting measures. A focus group discussion participant described the engagement of CMED as a redundant link in the learner driver testing process. FGD participants also pointed out that it would have been logical for the Minister to concentrate and pay more attention to resolving problems at the VID rather than adding new operational and administrative structures to the driver-testing process. A clear consensus that emerged from the focus group discussion was that driver pretesting was totally unnecessary. Only a minority hailed pretesting as a good thing and argued that if conducted properly, would result in an improvement in the quality of drivers.

\section{Has pretesting addressed corruption?}

In responding to the question on whether corruption had been reduced or precipitated following the introduction of pretesting, a number of views were expressed. The views can be divided into three categories. The first category comprised respondents who thought 
that corruption had been reduced. The second category comprised fence sitters who were either hesitant or reluctant to answer the question. Their answers included phrases such as: "perhaps it might have reduced/increased ...", "cannot tell ...", "not aware ...". Interestingly, most of the respondents in this category were learner drivers who had passed their test at either CMED or the VID. The third and final category (the majority) was of the view that corruption had increased post 1 September 2007. A sizeable proportion of learner drivers who expressed the negative view had failed their tests, which also shows that one has to be deeply frustrated to open up. The employment of ex-driving school instructors and the VID examiners as CMED assessors was frequently cited as one of the reasons that had fuelled corruption. Of the current CMED assessors, approximately 25 (45\%) are exdriving school instructors.

A learner driver who had failed her competence test spoke openly about corruption and said:

It [pretesting] has fuelled corruption. For you to make it, you have to pay someone. The examiners you see at CMED, some were previously at VID and driving schools. Corruption has been fuelled. It is not starting at CMED but from driving schools. I had been approached. [Female learner driver]

The only driver who admitted to having paid something to a driving school instructor had this to say:

I was made to pay $\mathrm{R} 450$ to an instructor who told me that it will be split between CMED and VID examiners. I paid the money not because I wanted to buy a licence. I knew I was a good driver but I was fed up with the number of times I had been through the long process. [Female driver]

Most people who expressed the view that the introduction of pretesting had worsened corruption pointed out that there were now more people to be bribed in a long chain. They further argued that corruption can be controlled when dealing with fewer people, but the more there are, the more difficult it becomes to contain. Respondents also expressed the view that bribes are paid during competence tests when the examiner and learner driver are by themselves in the vehicle. In such a situation, the temptation to request and pay a bribe is high as the environment to do so is conducive to it. An analysis of failures indicates that a greater proportion (approximately $80 \%$ ) of learner drivers fail in the yard and only about $20 \%$ fail town driving. Two compulsory tests that take place in the yard are parallel parking and reversing through drums. These two tests are done in public and there is nothing that the driving examiner can do to pass a learner driver if he or she hits a drum or fails to park the vehicle properly. In the case of town driving, a compromise can easily be reached as there will only be two people, the examiner and learner driver. Thus, the view 
that bribes are paid when the examiner and learner drivers are by themselves appear to be corroborated by the analysis of failure rates.

In respect of the contribution of pretesting in curbing corruption, there was consensus from the FGD that the new measure would precipitate corruption. The public warned against "exporting" bribery from driving schools and the VID to CMED and therefore not solving the corruption issue. The high cost of obtaining a licence was cited as a negative factor that is likely to encourage corrupt behaviour.

The introduction of driver pretesting was viewed by the public as a face-saving strategy as Government wants to be seen to be doing something whenever a major disaster occurs. "Why address the symptoms and not the real causes of the problem?" asked one FGD participant. Driver pretesting was also perceived as a way of raising money for the Government and not curbing corruption. Questions were raised as to why CMED, a state entity, was given the responsibility to conduct pretests and not another independent company.

Interestingly, in the period during which the study was being undertaken, three cases of corruption occurred which are highlighted in Box 2.

Box 2: Observed cases of bribery

Case 1: This case involved a driving school instructor who was paid US\$80 and promised a learner driver that she would pass the competency test. The CMED assessor who assessed the learner driver failed her, but completed forms for her to proceed to the VID. The learner driver failed the VID test and went back to the driving school instructor. The learner driver was advised to go to the Central Vehicle Registry (CVR) and obtain a duplicate PDL on the pretext that the original one was lost to enable her to go through the testing process before the expiration of the mandatory seven days. A different CMED assessor conducted the test and passed her but she went on to fail the VID test. After failing the second time (hitting a drum) she raised complaints and was taken to the VID Depot Manager. On interrogating the learner driver, it was established that she had taken the test only one day after failing the previous day. On further questioning, the learner driver let the cat out of the bag.

Case 2: This case involved a learner driver who had failed his test at the VID. After failing, he went back to CMED looking for his instructor. He was approached by a different CMED assessor who requested him to pay US $\$ 30$ to enable him to pass. The assessor who requested US\$30 tested him and passed him but he went on to fail the competence test at the VID. When the learner driver returned to CMED 
to reclaim his money he was told by the assessor who tested him to increase the payment. Unhappy with the request, the learner driver reported the matter to senior officials.

Case 3: The last case involved a learner driver bank employee who was requested to pay R1 000 by a driving school instructor to enable him to obtain a driving licence. He reported the matter to the VID and a trap was set leading to the arrest of the driving school instructor.

Source: CMED, VID, Personal encounter

From the foregoing, it is evident that corruption is still taking place. Most of it appears to emanate from driving school instructors. It is not clear how the movement of the bribe is facilitated in the chain. However, evidence from one of the three cases of corruption (Case 3 in Box 1) that occurred during the period of conducting the study indicates that a bribe can be demanded with no intention of passing it down the line but with the hope that the learner driver would pass the final competency test. It was also established that demands for bribes are not necessarily done to pass an incompetent learner driver. Some competent ones can be failed if they fail to pay a bribe.

The following observations, which clearly point to corrupt practices, were made by the author at CMED:

- In a number of instances at CMED, assessors would sift through learner drivers' application forms, probably looking for a specific applicant to test instead of picking the one on top. This practice raises suspicions of corruption.

- CMED assessors mingle with driving school instructors when the latter visit CMED offices to make bookings for learner drivers, a practice that may result in discussions hovering on corruption.

- An assessor was observed walking into the office with booking forms for a white woman at about 09.00. The forms were handed to the clerk who then requested the assessor to test her. The assessor refused to test the woman on the grounds that her appointment was at 10.00 notwithstanding the fact that there were no forms in the in-tray for learner drivers intending to be tested. The same assessor then went outside the office and enquired whether there were any learner drivers awaiting competence tests. This corroborates one interviewee's assertion that white people were not "easy bait", meaning that it is more difficult to coerce them to pay a bribe. 
- An assessor was observed intercepting a learner driver as the latter was approaching the CMED pretesting offices. The assessor took the booking invoice and placed it among other invoices and went outside the office. After a short while he returned to the office, took the same booking invoice, went outside the office and called the learner driver's name pretending not to know him. The practice of assessors meeting and escorting learner drivers in the booking office was observed to be prevalent.

\section{Has pretesting enhanced driver competence?}

One of the reasons for introducing pretesting was to improve driving skills in order to reduce accidents. It is therefore pertinent to address the question of whether the exercise has enhanced safety. The increase in the number of learner drivers who pass competency tests may be indicative of the fact that the quality of driver training has improved. Previously, the system used to produce drivers who were not properly trained. Prior to pretesting, there were also reports of learner drivers obtaining their driver's licences at home without being tested. Such a practice would not be possible in the present driver testing regimen. The new requirements have compelled driving schools to pay more attention to the way they train learner drivers. Driving schools are supposed to ensure that they recommend competent learner drivers to CMED and the latter has to do the same to the VID. Therefore, it can be surmised that driving skills have improved.

While driving skills may have improved, there is no evidence to show that this has translated into safety enhancement. Safety enhancement is not a product of proper training only but the incumbent driver's attitude is also a factor that can contribute to accidents.

This study was carried out 12 months after the new system was introduced. There has not been data available to ascertain whether the new driving system has resulted in the enhancement of safety. The period is also not long enough to assess the impact on safety. In the long run, it should be possible to relate driving skills to safety by examining trends in accidents and especially to compare accident records before and after 1 September 2007.

An interesting comment expressed by one interviewee was that frustration and the increased cost of obtaining a driver's licence is likely to result in some people not bothering to get tested and to drive illegally and therefore accident statistics may not necessarily go down. 


\section{DISCUSSION}

This section critiques issues emanating from the findings of the study as well as the decision and procedure that was taken in introducing the pretesting policy measure.

A recurring view expressed by the majority of respondents is that pretesting was not adding any value to the driver testing process as the pretesting agent, CMED, was undertaking work that was being repeated by the final competency testing department, the VID. The Wikipedia Encyclopedia and Concise Oxford English Dictionary respectively define pretesting as "a test taken for practice" and "a preliminary trial". It then follows that pretesting should be correctional and instructive and it is not the final test and thus, there is merit in the "no value addition" argument. To this end, CMED as the pretesting agent is supposed to take a learner driver through all the stages and provide a comprehensive report on the learner driver rather than an immediate termination of the test after an error has been made. The problem partly emanates from the failure by the Minister to clearly define CMED's responsibilities in the pretesting process.

Describing the infiltration of criminals in a supply chain, Atherton (2006) maintains "the very nature of products moving across multiple locations over long distances and under the responsibility of various corporations leaves plenty of room for vulnerability". This description is pertinent to the driver pretesting system which has a long chain with numerous administrative points. Clearly, weak points along the chain can easily be exploited. An obvious weak link in the chain is at CMED where former driving school instructors and the VID examiners who were alleged to be corrupt have been engaged. CMED should not have engaged ex-driving schools instructors and former VID examiners as assessors in the first place and there is need for the pretesting agent to train its own assessors who appreciate CMED work ethics. It is ironic that CMED knowingly engaged ex-driving school instructors who were alleged to be corrupt when the objective was to eradicate corruption. How can these supposedly corrupt instructors be expected to behave and act differently?

The majority of respondents complained about the high costs of obtaining a licence in the new testing regimen. The number of points where payments are made has increased from three (old regimen) to six (new regimen). Before pretesting was introduced, a learner driver would only pay for his or her driving lessons with the driving school, use of the driving school vehicle for the competence test, and the VID competency test charges. The new driver testing regimen which requires learner drivers to be pretested has introduced three additional costs, namely, the cost of the green book, vehicle hire for the CMED test and the CMED testing charge. The situation is compounded by the hyperinflationary environment, where costs change very frequently. At the time the study was conducted (October 2008) a class 4 (light vehicle) learner driver incurred Z\$2 313875 (then approximately US\$80). 
These costs were only applicable on the day of the survey as it was common for such costs to change on a daily basis. It has also to be noted that approximately 3 months before conducting the study; the Zimbabwean dollar had been "revalued" by the removal of 10 zeroes. Therefore, the $Z \$ 2313875$ represents a lot of money considering that the majority of people were at the time earning less than $Z \$ 1$ million per month. If the old testing regimen was retained, $30 \%$ of the costs representing about US $\$ 25$ would be saved. Thus, the process has become too long and costly and people quite rightly feel that they are being short-changed and not getting value for money. The cost analysis also explains the reduction in the number of learner drivers being tested.

The success of the new driver testing system will be judged on its contribution to safety enhancement. The improvement in learner driver pass rates does not provide sufficient evidence to make any conclusions on safety enhancement. Safety enhancement cannot be solely addressed by an improvement of pass rates. The individual driver's attitude also matters. For example, the failure to stop at a rail crossing by the driver which caused an accident (described in Box 1) that prompted the Minister to introduce the driver pretesting measures reflects an individual's attitude which cannot be verified when learner drivers are being tested. Secondly, this accident, including many others that have occurred in the country, could have been avoided if the laws of the country were observed and enforced. An analysis of the accident cited in Box 1 shows that the vehicle was overloaded, it was not roadworthy and the driver was below the mandatory age of 25 years required for one to drive a public service vehicle. These three areas cannot be addressed by driver pretesting. Therefore, as long as enforcement is weak, driver pretesting cannot meaningfully contribute to safety enhancement. The penalties for flouting traffic regulations are generally perceived as not being punitive enough to deter drivers from reckless behaviour on the road. The Minister should have firstly addressed the enforcement problem rather than introducing a new policy measure whose success is also dependent on strict enforcement.

The dramatic decline in the number of people seeking driving licences after the introduction of pretesting needs to be investigated. Where have these licence seekers gone? Either they have given up completely and are content not to drive or they have been too frustrated and resolved to drive illegally without a driver's licence as alleged by one interviewee. If the latter is the case, and pretesting has driven people away from legally acquiring a driver's licence, then this will have a long-term negative impact on safety.

A lesson learnt from the pretesting policy measure is that, merely introducing an intermediate driver testing agent is not the panacea for curbing corruption and driving skills improvement. While the Minister's intentions might have been good, the basic tenets of policy formulation and implementation were not followed. There was no attempt on the part of the Minister to consult the relevant stakeholders for their opinions on the practicality and desirability 
of the new policy measure. The views of policy recipients comprising driving schools, the VID, CMED, learner drivers, ZTSC, ZRP and Government departments should have been sought and taken on board. The Minister placed faith in the sole policy measure he enacted, without it being interrogated or alternative policies sought. Any policy measure results in outcomes which may be positive or negative. Thus, one cannot be absolutely certain that the proposed policies will produce the intended outcome. Driver pretesting measures were introduced in an environment with weak institutional support. As cited earlier on, enforcement and sanctions against drivers who break traffic regulations are generally weak. CMED assessors were also ill-equipped for the job as they were not given adequate training. Assessors' livelihoods are dependent on their employment and they are among the lowly paid people. The temptation to demand a bribe is therefore very high. Thus, the outcome has been disastrous as corruption has not been curbed and the general feeling is that it has increased.

No mechanisms to monitor and evaluate the outcomes of the policy measure were put in place by the Minister. There is need to closely monitor and evaluate the process and take timely corrective remedial measures where necessary. Evidently, expectations have been at variance with outcomes but the extent is unknown.

It was improper for the Minister to select and engage CMED, a Government-owned company, without according other companies an equal opportunity to provide the service. Clearly, the unilateral decision by the Minister was a demonstration of favouritism. The confinement of choice to one company meant that the job for pretesting was probably not given to the best company. As a Government-owned company, CMED suffers from the negative perception associated with most quasi bodies (parastatals) in Zimbabwe. Government companies are perceived as being inefficient and delivering services that do not give value for money.

\section{CONCLUSION AND RECOMMENDATIONS}

Governments worldwide are faced with the challenge to reduce road accidents that continue to claim the lives of people. The Zimbabwean Government attempted to address this issue by introducing a system that made it mandatory for all learner drivers to be pretested by an agent before undertaking a competency test. Ironically, the new system precipitated corruption principally due to lack of consultation and, inter alia, weak institutional structures. Apart from an increase in pass rates, which clearly cannot be taken to mean an improvement in driving skills, the study could not establish whether the new system had improved safety due to lack of data and the short period that had expired since the introduction of driver pretesting. 
The following recommendations are therefore pertinent:

- There is need to undertake a study in future to ascertain whether the new driver training procedure has had a positive impact on safety. To this end, it is recommended that Government puts in place a reliable national driver database system which currently is non-existent.

- With an unprecedented reduction in the number of learner drivers seeking drivers' licences, there is need to investigate and establish whether pretesting has not increased the number of illegal drivers.

- As a matter of urgency, there is need for Government to put in place mechanisms to monitor and evaluate the impacts of the driver pretesting policy measure. Such an evaluation would assist Government to take corrective measures where necessary.

- The need to strictly enforce traffic regulations and strengthen institutional structures cannot be overemphasised. These need to be properly addressed before any new measures can be considered. It must also be borne in mind that weak institutional structures are a recipe for corruption. 


\section{REFERENCES}

Anbard, N, Escaleras M \& Register, C. 2006. Traffic fatalities and public sector corruption. Kyklos, Blackwell Publishing, 59(3).

Atherton, P. 2006. Counterfeiting and corruption in the supply chain. Rodman Publishing.

Baker, D. 2004. The effects of driver training on simulated driving performance. Elsevier Ltd.

Bertrand M., Djankov, S. \& Mullainathan S. 2006. Does corruption produce unsafe drivers? www.doindbusiness.org/documents/Driving+tables_022006.pdf

Djankov, S., Mullainathan, S. \& Sequeira, S. 2008. The long way around: the real consequences of corruption in transport. Presentation at Harvard University.

Fisher, D.L., Pollatsek, A.P. \& Pradhan, A. 2006. Can novice drivers be trained to scan for information that will reduce the likelihood of a crash? Injury Prevention, Suppl 1.

Foss, R. 2007. Improving graduated driver licensing system: a conceptual approach and its implications. Journal of Traffic Research, 38(2).

Mayhew, D.R. \& Simpson, H.W. 2002. The safety value of driver education training. Traffic Injury Research Foundation (TIRF), Ottawa, Canada.

New South Wales Government (2007), Licence Tests, http://www.rta.nsw.gov.au/licensing/ tests/index.html

Paterson, W.D.O. \& Chauduri, P. 2007. Making inroads on corruption in the transport sector through control and prevention. In: The many faces of corruption: Tracking vulnerabilities at the sector level. Edited by J Edgardo Campos and Sanjay Pradhan, World Bank.

World Health Organisation (2004), World Report on Road Traffic Injuries and Prevention, Geneva

\section{Acknowledgement}

The assistance of Chipo Matonhodze, then a BSc (Hon.) student in Rural and Urban Planning at the University of Zimbabwe, in collecting data and information for the study is greatly appreciated.

\section{Acronyms}

CVR Central Vehicle Registry

FGD focus group discussion

GDL Graduated Driver Licensing

HMCs highly motorised countries
PDL Provisional Driver's Licence

VID Vehicle Inspection Department

ZTSC Zimbabwe Traffic Safety Council 